Thorax (1955), 10, 131.

\title{
MALIGNANT CHANGE IN BRONCHIECTASIS
}

BY

\author{
R. J. R. CURETON AND I. M. HILL \\ From St. Bartholomew's Hospital, London
}

(RECEIVED FOR PUBLICATION DECEMRER 10, 1954)

It has been known for some time (Deelman, 1924; MacKenzie and Rous, 1941 ; Pullinger, 1943 and 1945; Burrows and Clarkson, 1943; Burrows, Mayneord, and Roberts, 1937; Lacassagne, 1933; and others) that various types of injury can influence the development of experimentally produced tumours, hastening their development and localizing their site. In man, many instances have been recorded where a cancer has been found closely related to an area involved by former injury. Thus, for example, cancers have apparently developed in old burn scars (Treves and Pack, 1930), in association with varicose ulcers (Black, 1952), and sometimes in relation to chronic inflammatory lesions (lupus vulgaris, syphilitic lesions, etc.). It is possible that cancer may have some aetiological relation with such injury or chronic disease.

In the lung, instances have been recorded where cancer has been found, apparently originating in the walls of tuberculous cavities, in the "fibrous apical cap" (James and Pagel, 1944) and, according to several authors including Schwartz (1950), in bronchial scars resulting from tuberculous ulceration.

In recent years there have been recorded by several observers (Stewart and Allison, 1943; Petersen, Hunter, and Sneeden, 1949; Prior and Jones, 1952; Raeburn and Spencer, 1953; and others) a number of small early peripheral lung cancers, and evidence has been found that the majority of these tumours arose in areas of scarred lung.

Among these tumours there have been several which showed histological similarity to each other and resembled, in many respects, the " carcinoid" type of bronchial adenoma and also the basal-cell tumours of skin. The literature regarding these neoplasms has been well reviewed in the articles by Prior and Jones and by Raeburn and Spencer.

The case to be described falls into this group of tumours, although in this instance the neoplastic tissue was found widely disseminated in the lung.

\section{CASE History}

W. H., a male commercial traveller aged 36 years, had been investigated for cough and sputum of nine years' duration. At the age of 3 years he had had a lung infection and an empyema on the left was drained for some time. The detailed history of this illness is unobtainable, but three scars of drainage are present on the left chest wall. After this he remained well until the age of 27 , when he developed cough and sputum for the first time and was invalided from the Army.

His general condition remained good, but purulent sputum persisted, about $1 \frac{1}{2} \mathrm{oz}$. being raised daily, mostly at mid-day. In 1945 he had a haemoptysis of about $2 \mathrm{oz}$. on one occasion, followed by occasional staining of the sputum.

He was admitted to the Thoracic Department, St. Bartholomew's Hospital, on April 24, 1952, for investigation, when he was found to have grade 3 clubbing of the fingers, markedly impaired movement and air entry in the left chest, moist sounds throughout the left lung field, though mainly at the base, and some bronchospasm on both sides. Bronchoscopy on May 2 showed slight narrowing of the left upper lobe orifice, but there was no other abnormality apart from thick pus in the left main bronchus. Bilateral bronchograms showed total bronchiectasis of all segments of the contracted left lung, and a small area of cystic bronchiectasis in the right posterior and medial basal segments. After preliminary chemotherapy to reduce the sputum as far as possible, a left pneumonectomy was carried out on July 25 . Over the lower lobe, during the extrapleural separation of the lung, an epithelialized cavity was opened at the site of the old rib resection and a bone sequestrum found within. Muscle flaps were used in closing the chest wall, where excision of the scars had left a very thin chest wall.

Infection of the pneumonectomy space with penicillinresistant microaerophilic streptococci followed. The space was sterilized with chloramphenicol solution injections and streptokinase, and a small wound sinus excised and sutured. He was discharged healed and well on September 20.

In the next year he remained well and almost sputum free, but was readmitted to hospital on September 8 , 1953 , with a fever which had failed to respond to aureomycin. Aspiration of the left pleural space revealed 


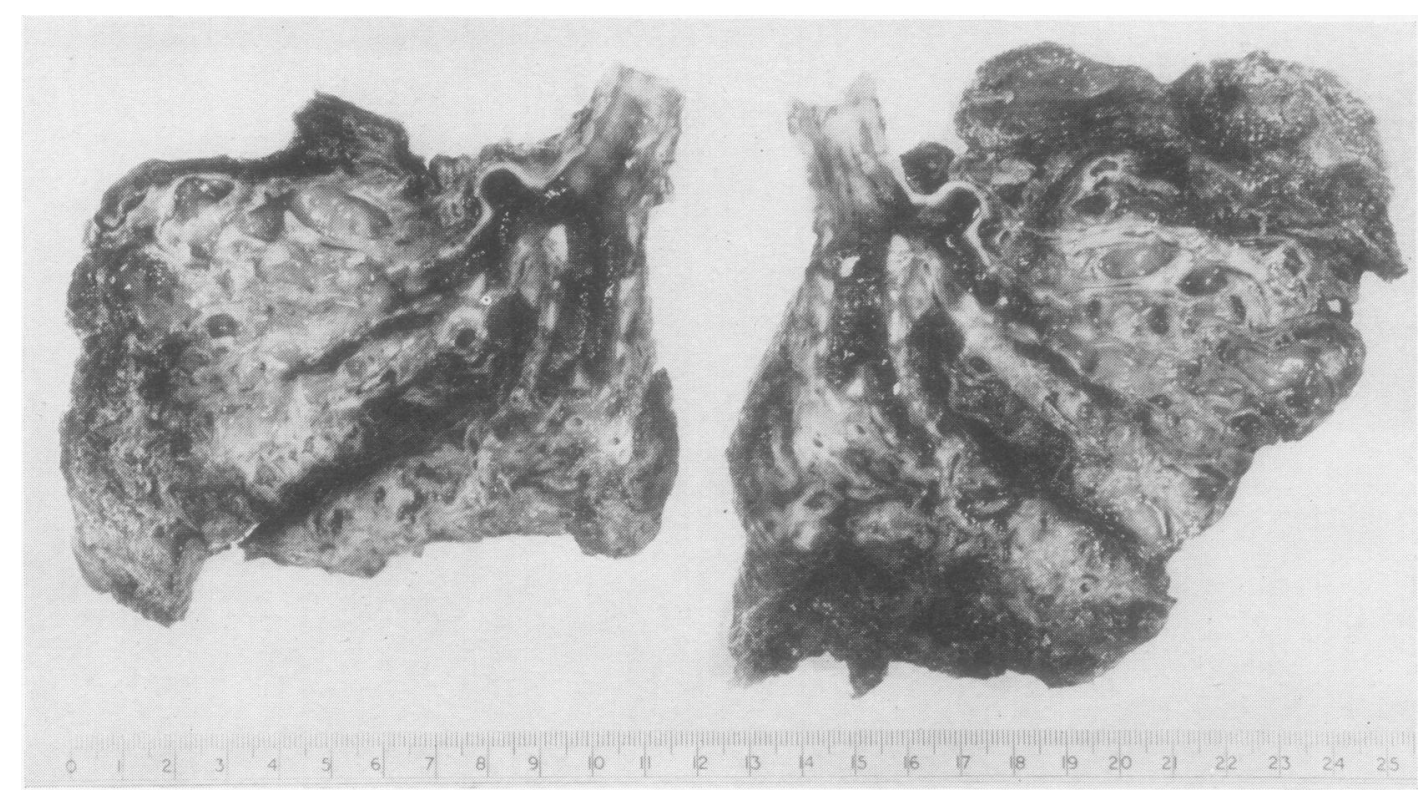

FIG. 1.-Slices of the shrunken, bronchiectatic left lung.

bloodstained pus, sterile aerobically, but growing a microaerophilic streptococcus which was penicillin sensitive. The space was sterilized with daily injections of $2 \mathrm{~m}$. units penicillin and he was discharged on October 2 , only to be readmitted three weeks later, again with fever. This time the left pleural space was opened by rib resection, all the pus and clot evacuated under penicillin cover, and the chest closed. The wound healed by primary intention and he has remained well and afebrile since. At no time has there been any evidence of bronchial fistula and at the second thoracotomy on October 30 there was no sign of recurrence of the tumour.

\section{Pathology}

The pneumonectomy specimen (Fig. 1) showed the whole lower lobe and most of the upper lobe to be affected by an advanced degree of tubular bronchiectasis. The dilated bronchi were filled with greyish mucus and little intervening lung tissue could be identified in the lower lobe. In the upper lobe some aerated lung was found, although this was partly collapsed and haemorrhagic. The hilar lymph nodes were small and not obviously involved by old or recent tuberculosis. Radiographs of the sliced specimen revealed no calcifications in the lymph nodes.

\section{Histology}

Sections of both upper and lower lobes show a widespread fibrosis of the lung tissue between the closely crowded bronchiectatic structures. A good deal of adipose tissue is also found between areas of scarring. The bronchi are extremely rugose due to folding of the mucosa over very prominent muscle bands. There is much proliferation of lymphoid tissue and hyperplasia of mucous glands in the bronchial walls (Figs. 2 and 3). Many bronchi contain pus. In numerous areas the muscle bands़े. are extremely prominent and often appear to become mixed in a haphazard manner with the fibrous and adipose tissue. The irregular folding of the bronchia@ mucosa seems also to merge with "duct-like ' extensions through the hypertrophied muscle coat of the bronchi (Fig. 4), and these extensions appean continuous with alveoli or other air spaces which remain in the fibrotic areas and which are lined by a cubical epithelium (Fig. 5). Many of these structures show focal hyperplastic thickening (Figs은. 4,6 , and 7) and one can almost imagine a series of gradations between this appearance and islands of frankly neoplastic tissue. The clumps of tumouro cells (Figs. 8 and 9) have a certain regularity in their. appearance and have a distinct resemblance to the basal-cell cancers of the skin.

In spite of their cytological appearances, however, the neoplastic masses are clearly infiltrating and? although perhaps not all of the spaces around the tumour clumps represent lymphatics, we think nevertheless that some are indeed lymphatic channels? lined by flattened endothelial cells (Fig. 9) $\stackrel{\mathbb{\Omega}}{\Omega}$ Metastatic tumour masses are found also in theo bronchopulmonary nodes and one tracheo-bronchial lymph node (Fig. 10). 
Fig. 2.-Folding of mucosa and hyperplasia of lymphoid tissue and mucous glands with adjacent adipose tissue. (Haematoxylin and eosin, $\times$ 32.)
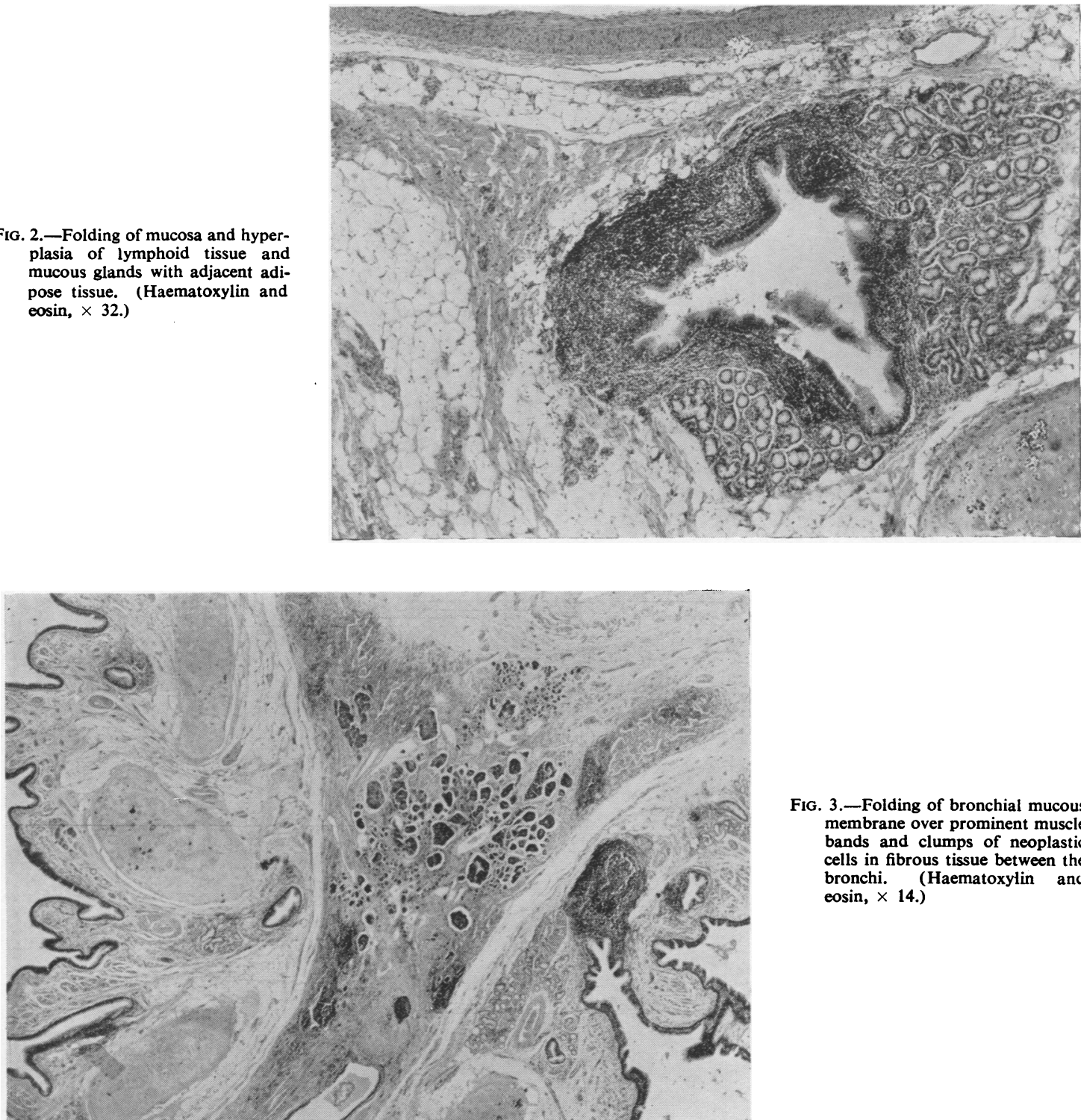

Fig. 3.-Folding of bronchial mucous membrane over prominent muscle bands and clumps of neoplastic cells in fibrous tissue between the bronchi. (Haematoxylin and eosin, $\times$ 14.)

The only other points of note are ossifying and calcifying cartilages in the bronchi, prominent obliterative endarteritis, the absence of any active or obsolete tuberculous lesions, and the fact that the neoplastic infiltration is found focally but widely disseminated both in the upper and lower lobes, which leads us to believe that this tumour may have a multicentric origin.

\section{Discussion}

These peripheral lung tumours, resembling basal cell cancer, appear to be in a small class of their own. They affect women more frequently than men, they have fairly distinctive histological features, and they also appear to behave generally in a benign manner. The previously recorded cases have, however, shown only small tumours in the peripheral lung fields and these have been found either accidentally during examination of post-mortem material or in pneumonectomy specimens. In each instance the advance of the tumours has been effectively terminated. Thus, while some authors have considered these neoplasms to represent oat-cell 


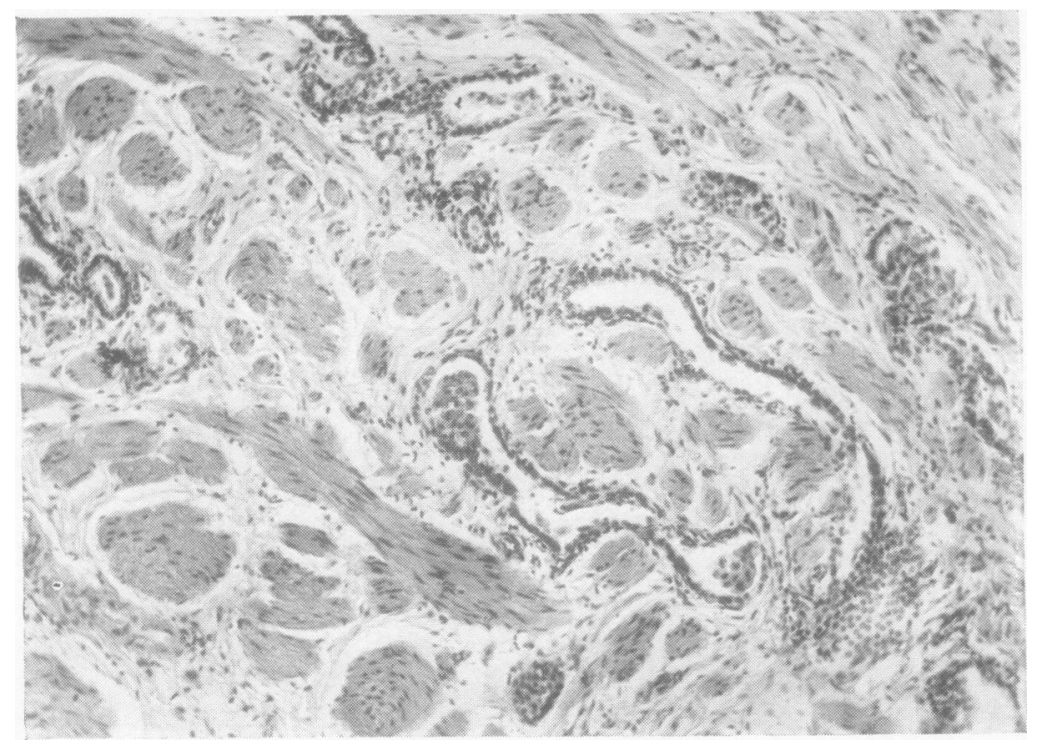

FIG. 4.-The duct-like structures extending through hypertrophied muscle bands. (Haematoxylin and eosin, $\times 92$.)

FIG. 5-Air spaces remaining in the scar tissue and lined by cubical epithelium. (Haematoxylin and eosin, $\times 116$.)

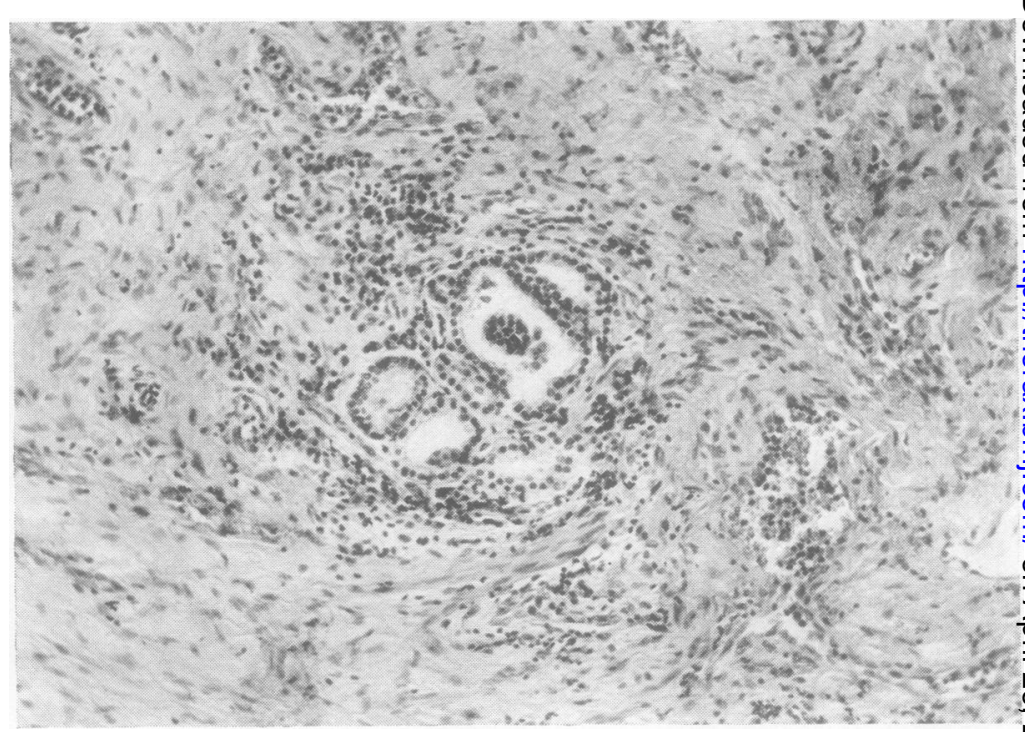

carcinomas, others have suggested that they are benign growths, perhaps related to bronchial adenomas. A multicentric origin has been suggested in one of Raeburn and Spencer's cases and in a case described by Gray and Cordonnier (1929).

In 18 out of 24 recorded cases, the tumours have been associated with bronchiectasis or bronchiolectatic changes in the lung, and it seems likely that the neoplastic proliferation arises in connexion with atypical cellular hyperplasia in areas of lung scarring. In spite of the frequency of bronchiectatic changes in the lungs which have been observed in these cases, it is clear that tumours are ver infrequently found in bronchiectasis. This rarity has been noted by Tuttle and Womack (1934) an by Niskanen (1949), and in our series of bronchiec tatic specimens at St. Bartholomew's Hospital this has been the only neoplasm found in 54 cases. It i possible, however, that some tumours may hav been missed owing to their small size. Stewart an ${ }^{\&}$ Allison (1943), for instance, found by accident, in histological section from a bronchiectatic lung, 

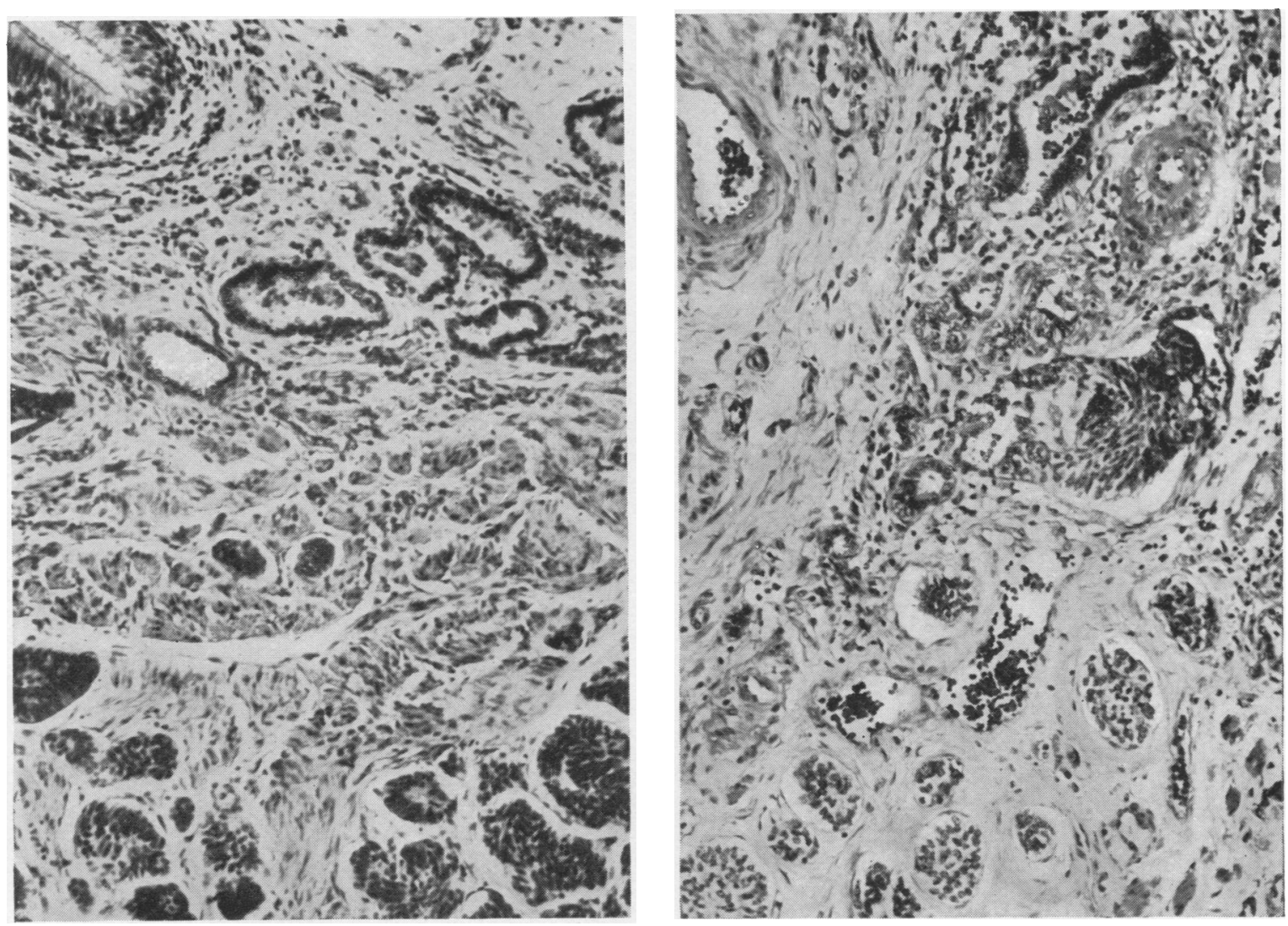

FIGS. 6 and 7.-Haematoxylin and eosin, $\times$ 155. Apparent transition between epithelial hyperplasia and neoplastic proliferation.

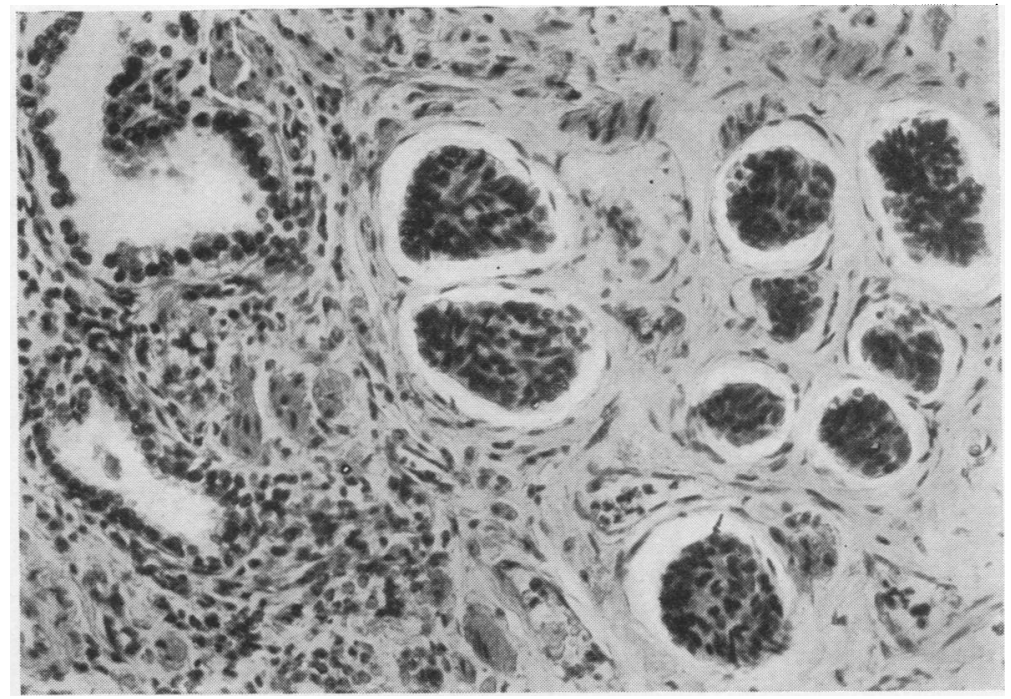

FIG. 8.-Clumps of neoplastic cells in scar tissue. (Haematoxylin and eosin, $\times 190$.) 


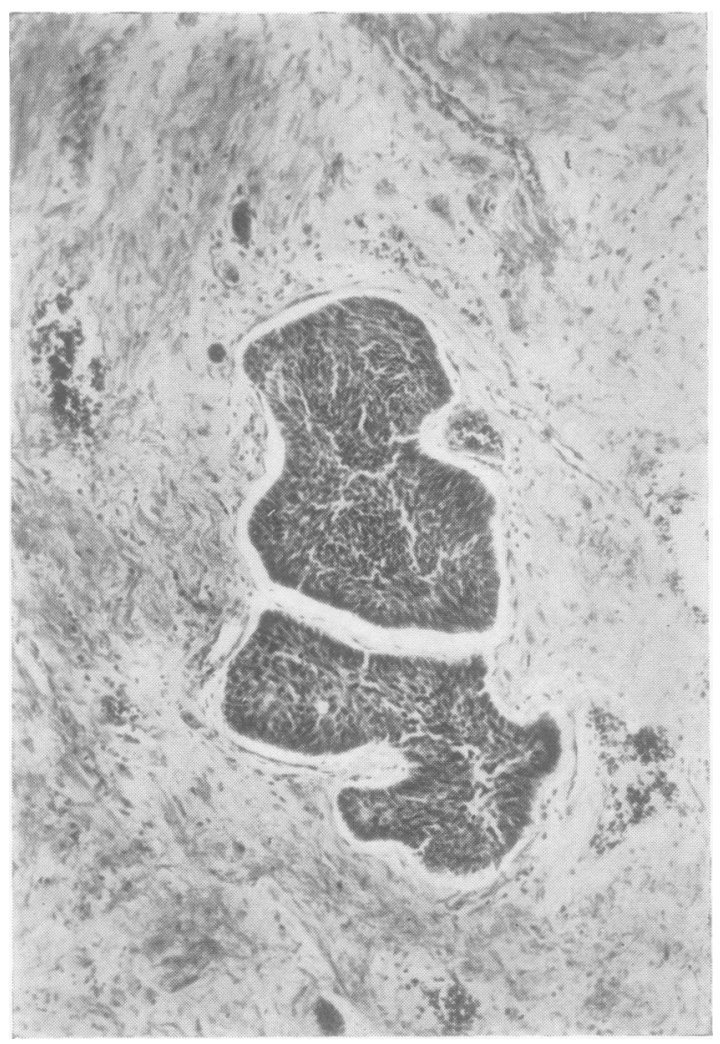

FIG. 9.-Tumour clumps apparently infiltrating lymphatics. The resemblance to basal-cell tumours is apparent. (Haematoxylin and eosin, $\times 100$.)

microscopic focus of growth $1.0 \mathrm{~mm} . \times 0.4 \mathrm{~mm}$. which had cytological features identical with those described above. Even in the case described here, where the tumour was widespread in all three lobes, its presence was only recognized when the histological sections were examined.

Womack and Graham (1941) have suggested that this type of tumour is associated with a congenital abnormality of the lung. We have found no evidence in our case to support this.

It is possible that the subsequent history of this case may indicate how malignant and how rapidly growing these tumours may be, for, if the neoplasm is arising multicentrically in relation to the bronchiectatic changes, similar neoplastic tissue may be present in the basal segments of the right lung.

It is at least evident from the histological characteristics that the tumour in this case is locally malignant with powers of metastasizing to the regional lymph nodes.

\section{SUMMARY}

The history and pathological appearances are described in a case of lung tumour associated with bronchiectasis.

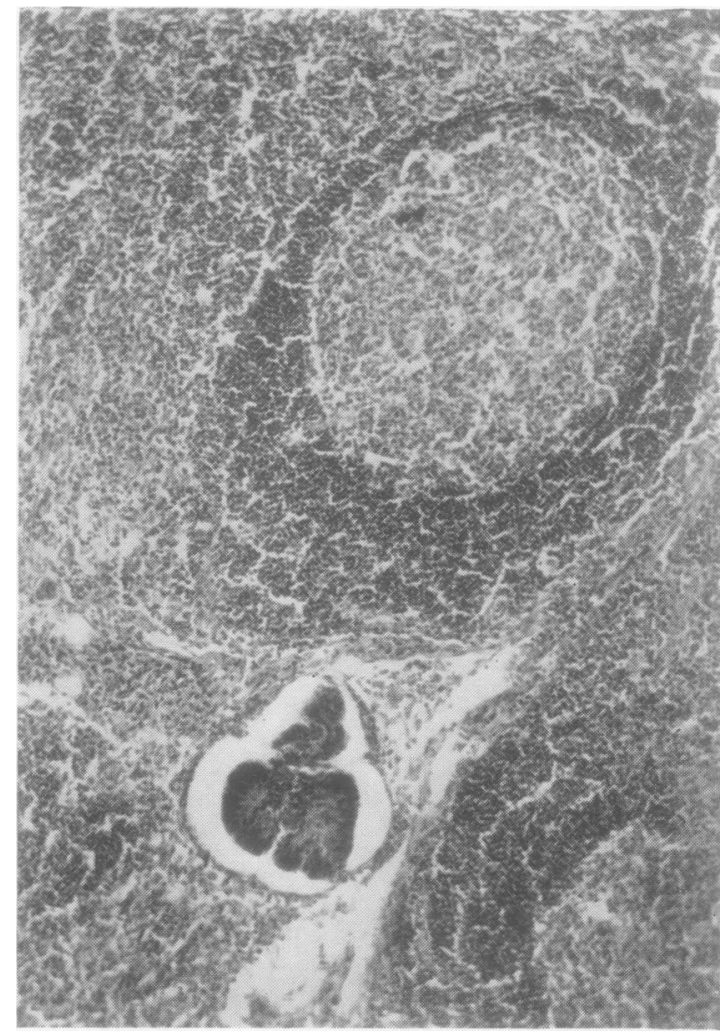

FIG. 10.-Tumour metastasis in a bronchopulmonary lymph node. (Haematoxylin and eosin, 160.)

The histological features, which resemble the basal-cell carcinomas of skin, are compared with similar tumours described in the literature.

The malignant nature of this particular tumour is indicated.

We should like to thank Professor J. W. S. Blacklock for much helpful criticism, Mr. J. W. Miller for histological sections, Mr. N. K. Harrison for the photograph of the lung specimen, and Dr. G. S. Sansom and Mr. $\mathrm{K}$. W. Iles for the photomicrographs.

\section{REFERENCES}

Black, W. (1952). Brit. J. Cancer, 6, 120.

Burrows, H., and Clarkson, J. R. (1943). Brit. J. Radiol., 16, 381 . - Mayneord, W. V., and Roberts, J. E. (1937). Proc. roy. Soc. $B ., 123,213$.

Deelman, H. T. (1924). Z. Krebsforsch., 21, 220.

Gray, S. H., and Cordonnier, J. (1929). Arch. Surg., Chicago, 19, 1618 .

James, I., and Pagel, W. (1944). Brit. J. Surg., 32, 85.

Lacassagne, A. (1933). C.R. Soc. Biol., Paris, 112, 562

MacKenzie, I.. and Rous, P. (1941). J. exp. Med., 73, 391.

Niskanen, K. O. (1949). Acta path. microbiol. scand., Suppl. 80. Petersen, A. B., Hunter, W. C., and Sneeden, V. D. (1949). Cancer, 2, 991 .

Prior, J. T., and Jones, D. B. (1952). J. thorac. Surg., 23, 224.

Pullinger, B. D. (1943). J. Path. Bact., 55, 301.

- (1945). Ibid., 57, 467.

Raeburn, C., and Spencer, H. (1953). Thorax, 8, 1

Schwartz, P. (1950). Beitr. Klin. Tuberk 103, 192.

Stewart, M. J., and Allison P. R (1943) J. Path. Bact, $55,105$.

Treves, N., and Pack, G. T. (1930). Surg. Gynec. Obstet, 51, 49.

Tuttle, W.'M., and Womack, N. A. (1934). J. thorac. Surg., 4, 125.

Womack, N. A., and Graham, E. A. (1941). Amer. J. Path., 17, 645. 